\section{Evaluation of stromal cell-derived factor-1 $\beta$ Gene polymorphism G801A among Egyptian patients with type 2 diabetes mellitus}

\author{
Hanan M Farhan ${ }^{1}$, Khadiga Abougabal ${ }^{1}$, Saly A Abd \\ Ellatif $^{1}$, Rania E Sheir ${ }^{2}$
}

Department of ${ }^{1}$ Clinical \& Chemical Pathology, Faculty of Medicine, Beni-Suef University, Beni-Suef, Egypt.

Department of ${ }^{2}$ Internal Medicine, Faculty of Medicine, BeniSuef University, Beni-Suef, Egypt.
The Egyptian Journal of Immunology Volume 28 (3), 2021: 94-101 www.Ejimmunology.org
Corresponding author: Hanan M Farhan, Department of Clinical \& Chemical Pathology, Faculty of Medicine, Beni-Suef University, Beni-Suef, Egypt.

Email: hananmohamedfarhan@gmail.com

\begin{abstract}
Stromal cell derived factor - 1 (SDF-1) is expressed by bone marrow derived stromal cells and stromal tissues in multiple organs. SDF-1 possesses diverse physiological and biochemical functions concerning autoimmunity and inflammation. SDF-1 gene polymorphisms play various roles in immune related diseases. This study aimed to evaluate association of SDF-1 $\beta$ G801A gene polymorphism and type 2 diabetes mellitus (T2DM) as regard prevalence and glycemic control. The study included hundred Egyptian subjects; 50 patients with T2DM recruited from the Internal Medicine Department, Beni-Suef University Hospital, and 50 age and sex matched healthy subjects. Participants were subjected to full clinical examination and routine laboratory investigations including fasting blood glucose, 2 hours post prandial blood glucose, serum creatinine, lipid profile and glycated hemoglobin $\left(\mathrm{HbA}_{1 c}\right)$. SDF-1 $\beta$ G801A gene polymorphism was analyzed using polymerase chain reaction -restriction fragment length polymorphism (PCR-RFLP). The frequency of GG and AG genotypes was higher in patients compared to controls with no statistical significance. Higher frequency of homozygous $G G$ genotype and $G$ allele were observed among patients with poor glycemic control $\left(\mathrm{HbA}_{1 \mathrm{c}} \geq 8 \%\right)$ compared to those with good glycemic control $\left(\mathrm{HbA}_{1 c}<8 \%\right)(P=0.001$ and 0.018 respectively). In conclusion, this study suggested an association between SDF- $1 \beta$ gene polymorphism and type 2 diabetes mellitus in Egyptian patients. Further studies are needed to confirm our observations.
\end{abstract}

Keywords: Stromal cell derived factor - 1 (SDF-1), gene polymorphism, type 2 diabetes mellitus (T2DM), polymerase chain reaction -restriction fragment length polymorphism (PCR-RFLP)

Date received: 23 January 2021; accepted: 22 April 2021

\section{Introduction}

In diabetes chronic low levels of inflammation in the pancreas and insulin-responsive tissues are accompanied by infiltration of lymphocytes and macrophages which causes a switch between anti- and pro-inflammatory profiles. Accordingly, diabetes is a disturbed balance between anti-inflammatory T-helper (Th) Th2 and $T$ regulatory cells (Tregs) subsets of $T$ cells versus pro-inflammatory Th1 and Th17 cells in 
favor of pro-inflammatory profile promoting polarization of M1 macrophages being the main producers of pro-inflammatory cytokines. ${ }^{1}$ Recruitment of autoreactive $T$ cells into pancreatic islets leads to inflammation referred to as insulitis that initiates diabetes development. $^{2}$

Stromal cell derived factor-1 (SDF-1) is a peptide chemokine initially identified in bone marrow derived stromal cells and then it was recognized to be expressed by stromal tissues of multiple organs. ${ }^{3}$ SDF-1 is also nominated as CXC motif ligand 12 (CXCL12). ${ }^{4}$ SDF-1 is a small 68 amino acids, 8 kDa chemokine which has been identified as the ligand for cell-surface CXC-chemokine receptor 4 (CXCR4) and CXCchemokine receptor 7 (CXCR7). ${ }^{5}$ Both SDF- 1 and its receptors are constitutively expressed by a variety of cells. ${ }^{6}$ Six SDF-1 isoforms have been reported SDF- $1 \alpha$, SDF-1 $\beta$, SDF- $1 \gamma$, SDF-1 $1 \delta$, SDF$1 \varepsilon$ and SDF- $1 \varphi$ where all share a common $N$ terminal amino acid sequence, but a distinct $\mathrm{C}$ terminus. $^{7}$

SDF-1 possesses diverse physiological and biochemical functions. ${ }^{8}$ It is considered to be a homeostatic chemokine, ${ }^{6}$ and SDF-1 plays a particularly important role in directing $T$ cell migration and therefore immune processes. ${ }^{2}$ Its role in autoimmunity and inflammation raises questions about its association with the pathogenesis of some immune related diseases including type 2 diabetes mellitus (T2DM). ${ }^{9}$

The gene encoding SDF- 1 is located on the human chromosome 10 q11.1. ${ }^{10}$ Single nucleotide polymorphisms (SNPs) in the SDF-1 gene play various roles in many pathophysiologic processes. ${ }^{8}$

Guanine to adenine ( $G$ to $A$ ) transition at position 801 of the $3^{\prime}$ untranslated region has been found to result in SDF-1 $\beta$ G801A gene polymorphism. $^{5}$ SDF-1 $\beta \quad$ G801A gene polymorphism has been indicated to be associated with diabetes as well as other immune related diseases. ${ }^{11}$

The aim of our study was to investigate the association between SDF-1 $\beta$ G801A gene polymorphism and T2DM as regard disease prevalence and glycemic control among Egyptian patients.

\section{Subjects and Methods}

\section{Subjects}

This study was carried out at the Faculty of Medicine, Beni-Suef University. The study was conducted on 100 subjects divided into 2 groups. Group I (patients group): Included 50 T2DM patients with age range (20-70 years). Patients with diabetic complications, inflammatory diseases, fibro proliferative disorders, autoimmune diseases and cancer were excluded from our study. Patients were recruited from Diabetic Outpatients Clinic and Internal Medicine Inpatient Department, BeniSuef University Hospital. Group $\Pi$ (control group): Included 50 apparently healthy volunteers with age range (20-80 years). Data confidentiality was preserved according to the Revised Helsinki Declaration of Bioethics $2008 .{ }^{12}$ Informed consent was obtained from all participants.

\section{Methods}

\section{Data collection and Biochemical analysis}

All participants were subjected to: 1-Full history taking including age, sex and disease history for selection of patients with no diabetic complications. 2- Full clinical examination including general examination for proper assessment of the clinical condition and also for exclusion of diabetic complications and other chronic diseases. 3- Routine laboratory investigations including fasting blood glucose (FBG), 2 hour post prandial blood glucose (2h PP $\mathrm{BG})$, total cholesterol, triglycerides (TG), low density lipoprotein cholesterol (LDL-C), high density lipoprotein cholesterol (HDL-C), serum creatinine and glycated hemoglobin $\left(\mathrm{HbA}_{1 \mathrm{c}}\right)$. Routine Laboratory investigations were analyzed on Bechman CX5 automated chemistry analyzer by its own commercial kits, Ireland.

\section{Genetic analysis}

\section{DNA extraction}

Peripheral blood samples of the participants were collected in tubes containing ethylenediaminetetraacetic acid (EDTA) for DNA isolation. The genomic DNA was extracted from each blood sample using GeneJET Whole Blood 
Genomic DNA Purification Mini Kit (Cat No\#FD0674, Lot/ 00187735, Fermentas Life Sciences, Thermo Fisher Scientific Inc., USA) according to the manufacturer's instructions.

\section{Genotyping of SDF-16 G801A Polymorphism}

SDF-1 G801A gene Polymorphism was determined using polymerase chain reactionrestriction fragment length polymorphism (PCRRFLP) assay. PCR primers were forward primer 5'- CAGTCAACCTGGGCAAAGCC-3' and reverse primer 5'- AGCTTTGGTCCTGAGAGTCC-3' elucidated earlier by Umapathy et al. ${ }^{3}$

PCR assay was performed for each sample in a final reaction volume of $25 \mu \mathrm{L}$, using 5 Template $\mu \mathrm{L}$ DNA, $12.5 \mu \mathrm{L}$ universal master mix, $1.5 \mu \mathrm{L} \mathrm{Mg} \mathrm{CL}, 1 \mu \mathrm{L}$ SDF-1 $\beta$ G801A forward primer, $1 \mu \mathrm{L}$ SDF-1 $\beta$ G801A reverse primer together with $4 \mu \mathrm{L}$ distilled water (DW). The PCR conditions were as follows: initial denaturation at $94^{\circ} \mathrm{C}$ for 5 minutes, 35 cycles of denaturation at $94^{\circ} \mathrm{C}$ for 30 seconds, annealing at $58^{\circ} \mathrm{C}$ for 30 seconds, extension at $72^{\circ} \mathrm{C}$ for 2 minutes, followed by a final extension at $72^{\circ} \mathrm{C}$ for $5 \mathrm{~min} .{ }^{3}$ All reactions were done using the thermal cycler Applied Biosystems (Perkin- Elmer 9600, USA). After amplification, the PCR products were treated at $37^{\circ} \mathrm{C}$ for 15 minutes with the restriction enzyme Fast Digest $\mathrm{Mspl}$ restriction endonuclease enzyme (Cat No. \# R0106S, lot no. 0551601, Fermentas Life Sciences, Thermo Fisher Scientific Inc., USA). ${ }^{3}$ The products were then resolved on $2 \%$ agarose gel electrophoresis containing ethidium bromide, and visualized using UV transilluminator. DNA molecular weight marker (Cat No. \# SM0373, Lot/ 244669, Fermentas Life Sciences, Thermo Fisher Scientific Inc., USA) was used to assess the size of PCR-RFLP products for interpretation of the different SDF-1 $\beta \quad$ G801A genotypes. Homozygous genotype (AA) was defined by the presence of one band $302 \mathrm{bp}$, genotype (GG) was defined by the presence of two bands 202 and $100 \mathrm{bp}$ while, heterozygous genotype (AG) was defined by the presence of three bands 302, 202 and 100 bp,. A representative gel showing the typical patterns of bands is presented in (Figure 1).

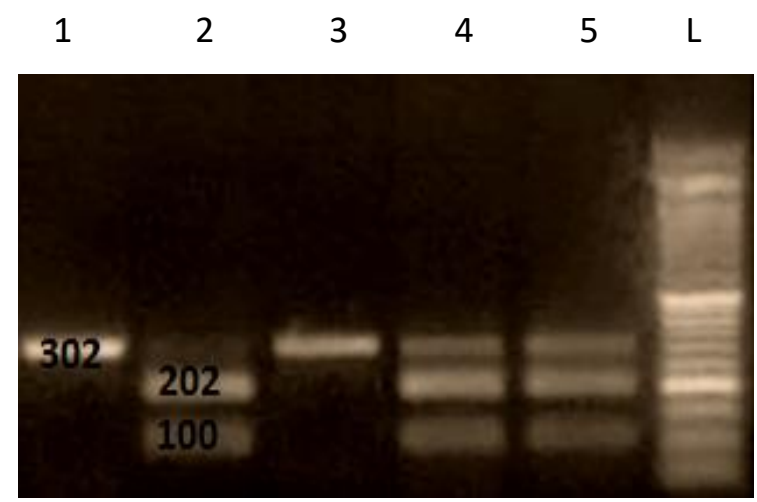

Figure 1. PCR-RFLP analysis of SDF-1 $\beta$ G801A gene polymorphism using Fast Digest Mspl restriction endonuclease enzyme by agarose gel electrophoresis. Lane $\mathrm{L}=$ Gene ruler $50 \mathrm{pb}$ DNA ladder (50-500 bp). Lane 1and $3=(\mathrm{AA})$ represented by 1 band $(302 \mathrm{bp})$. Lane $2=(\mathrm{GG})$ represented by 2 bands (202 and $100 \mathrm{bp})$. Lane 4 and $5=(\mathrm{AG})$ represented by 3 bands (302, 202 and 100 bp).

\section{Statistical methods}

Data were analyzed using IBM SPSS advanced statistics version 20 (SPSS Inc., Chicago, IL). Numerical data were expressed as mean and standard deviation (SD). Qualitative data were expressed as frequency and percentage. Chisquare test (Fisher's exact test) was used to examine the relation between qualitative variables. For quantitative data, comparison between two groups was done using MannWhitney test (non parametric t-test). Comparison between 3 groups was done using Kruskal-Wallis test (non-parametric ANOVA). Odds ratio (OR) with it $95 \%$ confidence interval $(\mathrm{Cl})$ were used for risk estimation. A $P$-value < 0.05 was considered significant. ${ }^{13}$

\section{Results}

Fifty T2DM patients were included in the study as patients group; 15 males (30\%) and 35 females (70\%) with mean age $(50.32 \pm 10.82$ years). Fifty apparently healthy volunteers were included as control group; 24 males (48\%) and 26 females (52\%) with mean age $(50.80 \pm 11.88$ years). The control subjects were age and sex matched with patients $(P=0.833$ and 0.051 respectively).

By evaluating the different studied laboratory parameters, diabetic patients group showed statistically significant higher concentration 
than control group as regard FBS, $2 \mathrm{~h}$ PP $\mathrm{BG}$, total cholesterol, TG, LDL-C and $\mathrm{HbA}_{1 c}(P=$ $<0.001,<0.001,<0.001,<0.001,0.003$ and $<0.001$ respectively). Diabetic group showed statistically significant lower concentration of
HDL-C than control group $(P=<0.001)$. There was no statistically significant difference of serum creatinine concentration between the two studied groups $(P=0.246)$ (Table 1$)$.

Table 1. Laboratory findings in Egyptian diabetic patients and controls.

\begin{tabular}{|c|c|c|c|}
\hline Variable & $\begin{array}{c}\text { Patients } \\
(n=50) \\
\text { Mean } \pm \text { SD }\end{array}$ & $\begin{array}{c}\text { Controls } \\
(n=50) \\
\text { Mean } \pm \text { SD }\end{array}$ & ${ }^{*} P$-Value \\
\hline $\mathrm{FBS}(\mathrm{mg} / \mathrm{dl})$ & $179.02 \pm 57.09$ & $86.82 \pm 6.42$ & $<0.001$ \\
\hline 2h PP BG (mg/dl) & $255.84 \pm 72.52$ & $126.40 \pm 10.76$ & $<0.001$ \\
\hline Total cholesterol (mg/dl) & $208.36 \pm 47.01$ & $162.96 \pm 9.79$ & $<0.001$ \\
\hline $\mathrm{TG}(\mathrm{mg} / \mathrm{dl})$ & $163.38 \pm 77.746$ & $120.78 \pm 7.544$ & $<0.001$ \\
\hline $\mathrm{HDL}-\mathrm{C}(\mathrm{mg} / \mathrm{dl})$ & $45.76 \pm 4.55$ & $61.92 \pm 15.66$ & $<0.001$ \\
\hline LDL-C (mg/dl) & $109.68 \pm 38.16$ & $93.00 \pm 5.20$ & 0.003 \\
\hline $\mathrm{HbA}_{1 \mathrm{c}}(\%)$ & $8.46 \pm 1.68$ & $5.67 \pm 0.36$ & $<0.001$ \\
\hline Creatinine (mg/dl) & $0.80 \pm 0.16$ & $0.84 \pm 0.15$ & NS \\
\hline
\end{tabular}

FBG: fasting blood glucose, 2h PP BG: 2 hour post prandial blood glucose, TG: triglycerides, HDL-C: high density lipoprotein cholesterol, LDL-C: low density lipoprotein cholesterol, $\mathrm{HbA}_{1 \mathrm{cc}}$ glycated hemoglobin, intergroup comparison was done using Independent $\mathrm{t}$-test, ${ }^{*} P$ value $>0.05$ is not significant (NS).

There was no statistically significant difference between the two studied groups as regard alleles ( $P=0.084$ and 0.891 respectively) (Table frequency of SDF-1 $\beta$ G801A genotypes and 2).

Table 2. SDF-1 $\beta$ G801A genotypic and allelic frequencies in Egyptian diabetic patients and controls.

\begin{tabular}{lccc} 
Genotype & $\begin{array}{c}\text { Patients }(\mathrm{tn}=50) \\
\text { Frequency } n(\%)\end{array}$ & $\begin{array}{c}\text { Controls }(\mathrm{tn}=50) \\
\text { Frequency } n(\%)\end{array}$ & *P-Value \\
\hline Homozygous genotype (GG) & $20(40 \%)$ & $26(52 \%)$ & NS \\
Heterozygous genotype (AG) & $28(56 \%)$ & $18(36 \%)$ & \\
Homozygous genotype (AA) & $2(4 \%)$ & $6(12 \%)$ & NS \\
\hline Allele (G) & $68(68 \%)$ & $70(70 \%)$ & \\
Allele (A) & $32(32 \%)$ & $30(30 \%)$ &
\end{tabular}

$\mathrm{tn}=$ total number, $\mathrm{n}=$ number positive, intergroup genotype and allelic distribution was done using Chi-Square Test, ${ }^{*} P$ value $>0.05$ is not significant (NS).

A comparison of SDF-1 801 frequencies of genotypes $G G$ and $A G$ versus $A A$ showed higher frequencies of $G G$ and $A G$ in diabetic patients than controls but it did not reach statistical significance $(p=0.134)$ (Table 3 ).

Table 3. Distribution of SDF-1 $\beta$ G801A genotypes in Egyptian diabetic patients and controls.

\begin{tabular}{lcccc} 
Genotype & $\begin{array}{c}\text { Patients }(\mathrm{tn}=50) \\
\text { Frequency } n(\%)\end{array}$ & $\begin{array}{c}\text { Controls }(\mathrm{tn}=50) \\
\text { Frequency } \mathrm{n}(\%)\end{array}$ & OR $(95 \% \mathrm{Cl})$ & ${ }^{*} P$-Value \\
\hline GG and AG & $48(96 \%)$ & $44(88 \%)$ & $0.495(0.215-1.135)$ & NS \\
AA & $2(4 \%)$ & $6(12 \%)$ & & \\
\hline
\end{tabular}

$\mathrm{tn}=$ total number, $\mathrm{n}=$ number positive, intergroup genotype distribution was done using Binary logistic regression,

*P value $>0.05$ is not significant (NS). 
Statistical comparison between SDF-1 $\beta$ G801A genotypes among diabetic patients at $\mathrm{HbA}_{1 c}$ cutoff $8 \%$ showed statistically significant higher frequency of homozygous GG genotype among patients with $\mathrm{HbA}_{1 \mathrm{c}} \geq 8 \%$ compared to patients with $\mathrm{HbA}_{1 \mathrm{c}}<8 \%(P=0.001)$ (Table 4). AA genotype was not included in this comparison due to its small number.

Table 4. Frequency of SDF-1 $\beta$ G801Agenotypes GG and $A G$ at $\mathrm{HbA}_{1 c}$ cutoff $8 \%$ among Egyptian diabetic patients.

\begin{tabular}{ccccc} 
& \multicolumn{2}{c}{ Genotype } & OR (95\% CI) & P-Value \\
\cline { 2 - 3 } HbA1c & GG Frequency (\%) & AG Frequency (\%) & & \\
\hline $8(\%)$ & $3(15 \%)$ & $18(64.3 \%)$ & $0.098(0.023-0.418)$ & 0.001 \\
\hline $8(\%)$ & $17(85 \%)$ & $10(35.7 \%)$ & & \\
\hline
\end{tabular}

Intergroup genotype distribution was done using Binary logistic regression, $P<0.05$ is significant.

Statistical comparison as regard SDF-1 $\beta$ G801A allotypes among patients at $\mathrm{HbA}_{1 \mathrm{c}}$ cutoff $8 \%$ showed statistically significant higher frequency of $\mathrm{G}$ allele among patients with $\mathrm{HbA}_{1 \mathrm{c}} \geq 8 \%$ compared to patients with $\mathrm{HbA}_{1 \mathrm{c}}<8 \%(P=$ 0.018) (Table5).

Table 5. Frequency of SDF-1 $\beta$ G801A allotypes $A$ and $\mathrm{G}$ at $\mathrm{HbA}_{1 \mathrm{c}}$ cutoff $8 \%$ among Egyptian diabetic patients.

\begin{tabular}{lccccc} 
& \multicolumn{3}{c}{ Alleles } & OR $(95 \% \mathrm{Cl})$ & P-Value \\
\cline { 2 - 3 } HbA1c & $\begin{array}{c}\mathrm{A} \\
\mathrm{n}(\%)\end{array}$ & $\begin{array}{c}\mathrm{G} \\
\mathrm{n}(\%)\end{array}$ & & \\
\cline { 2 - 3 }$<8(\%)$ & $18(56.2 \%)$ & $24(35.3 \%)$ & $0.424(0.180-1.000)$ & 0.018 \\
\hline$\geq 8(\%)$ & $14(43.8 \%)$ & $44(64.7 \%)$ & & \\
\hline
\end{tabular}

Intergroup allelic distribution was done using Binary logistic regression, $P<0.05$ is significant.

\section{Discussion}

Diabetes is a common global health problem that affects more than 170 million people worldwide. ${ }^{14}$ Worldwide prevalence of diabetes in adults was $5.1 \%$ in 2003 and is predicted to increase to $6.3 \%$ by the year $2025 .{ }^{15}$ The benefits of glycemic control and diabetic complications could provide new strategies for disease pathogenesis, risk assessment and novel interventions to reduce diabetic complications. ${ }^{16}$

Our study investigated SDF-1 $\beta$ G801A gene polymorphism in a sample of Egyptian population with T2DM as regard disease prevalence. On comparing different genotypes, GG and AG genotypes showed higher frequency in diabetic patients than control without reaching statistical significance. Previous studies found that GG genotype frequency was significantly associated with T2DM when compared to healthy controls. ${ }^{9,3,17}$ SDF-1 G allele was considered as a risk allele and $A$ to be the protective allele for T2DM in south Indian population. ${ }^{3}$ SDF-1 A allele conferred significant protection against diabetes mellitus. ${ }^{18}$ In another study, no statistically significant difference was reported between T2DM patients and healthy controls regarding genotypes and alleles of SDF-1 $\beta$ G801A gene. ${ }^{4}$

Retention of Tregs in bone marrow by SDF-1 disturbs the balance of $T$ cells in favor of autoreactive T cells. ${ }^{19}$ SDF-1 possesses a proinflammatory role and recruits monocytes which after differentiation secrete pro- 
inflammatory cytokines suggesting that SDF-1 axis induces M1 macrophage accumulation, subsequent inflammatory cytokine production and finally insulin resistance. ${ }^{20}$ Several studies have investigated SDF1 with diabetic complications which reported that SDF-1 plays various biological effects regarding the microenvironment created during repair processes such as angiogenesis, recruitment of bone marrow-derived progenitor cells and endothelial progenitor cells (EPCS). ${ }^{8}$ SDF- 1 expression in the kidney increases during acute renal failure, resulting in homing of progenitor cells to injured kidney. ${ }^{21}$ SDF-1 injury response mechanisms in diabetic retinopathy contribute to angiogenesis by recruiting EPCs to site of vascular injury. ${ }^{22,}{ }^{23}$ SDF-1/CXCR4 pathway is involved in diabetic retinopathy possibly by increasing cell viability. ${ }^{24}$ The general conclusion regarding SDF-1 role in diabetes and diabetic complications is that SDF- 1 walks a thin line between morbid and protective effects. ${ }^{25}$

In our study, we aimed to evaluate the significance of SDF-1 $\beta$ G801A gene polymorphism regarding glycemic control among T2DM patients. To fulfill this objective, patients with diabetic complications were excluded to avoid their influence on the results. $\mathrm{HbA}_{1 \mathrm{c}}$ is the gold standard for long-term monitoring of glycemic control, correlation with occurrence of long term micro and macrovascular complications and treatment target by most clinicians. ${ }^{26,27,28}$ Accordingly, in our study, $\mathrm{HbA}_{1 \mathrm{c}}$ was assayed as glycemic control index among diabetic patients where statistically significant higher frequency of homozygous $G G$ genotype and $G$ allele among patients with $\mathrm{HbA}_{1 \mathrm{c}} \geq 8 \%$ was found compared to patients with $\mathrm{HbA}_{1 \mathrm{c}}<8 \%(\mathrm{p}=0.001$ and 0.018 , respectively); assuming an association between SDF-1 $\beta$ G801A gene polymorphism and poor glycemic control. Our assumption can find its explanation based on researchers who reported that SDF-1B G801A gene polymorphism has been found to up regulate the expression of SDF-1, ${ }^{3,10,29}$ and accordingly SDF-1 binds to the specific receptor CXCR4 participating in various immune and inflammation reactions. ${ }^{30}$ This was ascertained by another study which reported that SDF-1/
CXCR4 axis is one of the components of a complex signaling network that can act in synergy with other factors to regulate $\beta$-cell mass. ${ }^{31}$ Additionally, the preceded explanation can be verified where SDF-1 was stated as a crucial cellular and tissue mediator under diverse conditions including pancreatic $\beta$-cell apoptosis. $^{32}$ Also, SDF1 was reported to facilitate the processes of $\beta$-cell destruction. ${ }^{4}$

In conclusion, this study suggested an association between SDF-1 $\beta$ gene polymorphism and type 2 diabetes mellitus in Egyptian patients. $\mathrm{G}$ allele may be a risk factor for poor glycemic control among diabetic Egyptian patients. Further studies on large cohort of diabetic patients, are needed to confirm our findings.

\section{Author Contributions}

HMF, KA, SAA, and RES acquired, analyzed and interpreted data. SAA performed statistical analysis. HMF, KA and SAA were major contributors in writing the manuscript. All authors read and approved the final manuscript.

\section{Declaration of Conflicting Interests}

The author(s) declared no potential conflicts of interest with respect to the research, authorship, and/or publication of this article.

\section{Funding}

This research did not receive any specific grant from funding agencies in the public, commercial, or notfor-profit sectors.

\section{Ethical approval}

The study was approved by the Research Ethical Committee, Faculty of Medicine, Beni-Suef University (approval number FMBSUREC/07022021/ Sheir).

\section{Informed consent}

A signed consent form was obtained from each study participant.

\section{References}

1. Esser N, Legrand-Poels S, Piette J, et al. (2014) Inflammation as a link between obesity, metabolic 
syndrome and type 2 diabetes. Diabetes Res Clin Pract. 105(2): 141-50.

2. Leng $Q$, Nie $Y$, Zou $Y$, et al. (2008) Elevated CXCL12 expression in the bone marrow of NOD mice is associated with altered $\mathrm{T}$ cell and stem cell trafficking and diabetes development. BMC Immunol 9: 51.

3. Umapathy D, Krishnamoorthy E, Muthukumaran $P$, et al. (2013) Stromal cell-derived factor (SDF-1 $\beta$ ) gene single nucleotide polymorphism at position G801A is associated with type 2 diabetes mellitus in a south Indian population. International Journal of Genetic Engineering 3(1): 1-5.

4. Karimabad MN and Hassanshahi G (2015) Significance of CXCL12 in type 2 diabetes mellitus and its associated complications. Inflammation 38(2): 710-717.

5. Wang X, Zhang H, He H et al. (2014) Prognostic value of stromal cell-derived factor 1 expression in patients with gastric cancer after surgical resection. Cancer Sci 105(11): 1447-1456.

6. Martins-Green M, Petreaca M, Wang L (2013) Chemokines and their receptors are key players in the orchestra that regulates wound healing. Advances in Wound Care 2(7): 327-347.

7. Liang Y, Ping W, Bian L (2015) Cloning, expression and identification of an isoform of human stromal cell derived factor-1 $\alpha$. Exp Ther Med 9(5): 17511756.

8. Feng L, Nian S, Nian $Y$ et al. (2014) A single nucleotide polymorphism in the stromal cell-derived factor 1 gene is associated with coronary heart disease in Chinese patients. Int J Mol Sci 15(6): 11054-11063.

9. Derakhshan R, Arababadi MK, Ahmadi Z, et al. (2012) Increased circulating levels of SDF-1 (CXCL12) in type 2 diabetic patients are correlated to disease state but are unrelated to polymorphism of the SDF$1 \beta$ gene in the Iranian Population. Inflammation 35(3): 900-4.

10. Wu N, Zhang $X$, Jia $P$, et al. (2015) Lack of an association between the SDF-1 rs1801157 polymorphism and coronary heart disease: A metaanalysis. Sci Rep 5: 11803.

11. Yousefipour GA, Haghshenas MR, Yahyazadeh S, et al. (2011) Stromal cell derived factor-1 genetic variation at locus 801 in patients with myasthenia gravis. Iran J Immunol 8(2): 90-95.

12. World Medical Association (2008) Declaration of Helsinki: ethical principles for medical research involving human subjects. The 59th WMA General Assembly,Seoul, South Korea.

13. Dawson B and Trapp RG (2001) Basic and clinical biostatistics, 3rd edn. McGraw-Hill, New York.
14. Nafees H, Khare S, Jain Sh, et al. (2016) Association of SDF-1 $\beta$ gene single nucleotide polymorphism in type 2 diabetes mellitus patients in north Indian population. Int J Anat Res 4(3): 2854-59. 15. Mahwish UN, Jaffer AT, Mughni Chisti GM, et al. (2014) A preliminary study on NPHS2 gene polymorphism (R229Q) in diabetic nephropathy patients from south India. J Cell Sci Molecul Biol 1(2): 108.

16. Ma RCW (2016): Genetics of cardiovascular and renal complications in diabetes. J Diabetes Investig 7: 139-154.

17. Rizvia S, Razaa ST, Mahdia F, et al. (2018) Genetic polymorphisms in KCNJ11 (E23K, rs5219) and SDF $1 \beta$ (G801A, rs1801157) genes are associated with the risk of type 2 diabetes mellitus. British journal of biomedical science 75(1):1-6.

18. Dhamodharan U, Viswanathan V, Krishnamoorthy E, et al. (2015) Genetic association of IL-6, TNF- $\alpha$ and SDF-1 polymorphisms with serum cytokine levels in diabetic foot ulcer. Gene 565(1): 62-7.

19. Aboumrad E, Madec AM, Thivolet C (2007) The CXCR4/ CXCL12 (SDF-1) signalling pathway protects non-obese diabetic mouse from autoimmune diabetes. Clin Exp Immunol 148(3): 432-9.

20. Kim D, Kim J, Yoon JH, et al. (2014) CXCL12 secreted from adipose tissue recruits macrophages and induces insulin resistance in mice. Diabetologia 57(7): 1456-65.

21. Sayyed SG, Hägele $H$, Kulkarni OP, et al. (2009) Podocytes produce homeostatic chemokine stromal cell-derived factor-1/CXCL12, which contributes to glomerulosclerosis, podocyte loss and albuminuria in a mouse model of type 2 diabetes. Diabetologia 52(11): 2445-54.

22. Ceradini DJ, Kulkarni AR, Callaghan MJ, et al. (2004) Progenitor cell trafficking is regulated by hypoxic gradients through HIF-1 induction of SDF-1. Nat Med 10:858-64.

23. Butler JM, Guthrie SM, Koc M, et al. (2005) SDF-1 is both necessary and sufficient to promote proliferative retinopathy. J Clin Invest; 115(1): 86-93.

24. Deng L, Jia J, Yao J, et al (2019) Stromal cellderived factor 1 (SDF-1) and its receptors CXCR4 improves diabetic retinopathy. Bioscience, Biotechnology and Biochemistry 83 (6): 1072- 1076.

25. Vidaković M, Grdović N, Dinić S, et al. (2015) The importance of the CXCL12/CXCR4 axis in therapeutic approaches to diabetes mellitus attenuation. Front Immunol 6: 403.

26. Carrera Boada CA and Martínez-Moreno JM (2013) Current medical treatment of diabetes type 2 
and long term morbidity: how to balance efficacy and safety? Nutr Hosp 28(2): 3-13.

27. Yousefzadeh G, Shokoohi M, Najafipour H (2015) Inadequate control of diabetes and metabolic indices among diabetic patients: A population based study from the Kerman Coronary Artery Disease Risk Study (KERCADRS). Int J Health Policy Manag 4(5): 271277.

28. Smulders $Y$ and Serne E (2018) Is HbA1c a good diagnostic test for (pre) diabetes in cardiac rehabilitation patients? Eur J Prevent Cardiol 25(5): 462-463.

29. Kara T, Akaltun I, Cakmakoglu B, et al. (2018) An investigation of SDF1/CXCR4 gene polymorphisms in autism spectrum disorder: a family-based Study. Psychiatry Investigation 15(3): 300-305.
30. He G, Ma M, Yang W, et al. (2017) SDF-1 in mammary fibroblasts of bovine with mastitis induces EMT and inflammatory response of epithelial cells. Int J Biol Sci 13:604-14.

31. Yano T, Liu Z, Donovan J, et al. (2007) Stromal cellderived factor-1 (SDF-1)/CXCL12 attenuates diabetes in mice and promotes pancreatic $\beta$-cell survival by activation of the prosurvival kinase akt. Diabetes 56(12): 29462957.

32. Takashima S, Fujita H, Fujishima H, et al. (2016) Stromal cell-derived factor-1 is upregulated bydipeptidyl peptidase-4 inhibition and has protective roles in progressive diabetic nephropathy. Kidney International 90 (4): 783-796. 